\title{
Future changes to high impact weather in the UK
}

\author{
Helen M. Hanlon ${ }^{1}$ (D) Dan Bernie ${ }^{1}$ (D) $\cdot$ Giulia Carigi $^{1,2}$ (D) Jason A. Lowe ${ }^{1,3}$ (D)
}

Received: 8 February 2020 / Accepted: 19 April 2021 / Published online: 30 June 2021

(C) Crown 2021

\begin{abstract}
High impact weather events such as extreme temperatures or rainfall can cause significant disruption across the UK affecting sectors such as health, transport, agriculture and energy. In this study we draw on the latest set of UK climate projections, UKCP, to examine metrics relating to high-impact weather over the UK and how these change with different levels of future global warming from $1.5{ }^{\circ} \mathrm{C}$ to $4{ }^{\circ} \mathrm{C}$ above pre-industrial. The changes to these hazards show increases in the frequency of extremely hot days and nights, with a UK average increase in hot days of between 5 and 39 days per year between $1.5^{\circ} \mathrm{C}$ and $4{ }^{\circ} \mathrm{C}$ of global warming. Projections indicate an increase in cooling degree days of 134-627\% and an increase in growing degree days of 19-60\% between $1.5{ }^{\circ} \mathrm{C}$ and $4{ }^{\circ} \mathrm{C}$ of global warming. Extremely hot nights, which are currently rare, are emerging as more common occurrences. The frequency of high daily temperatures and rainfall increase systematically, while the frequency of very cold conditions (based on days where temperatures fall below $0{ }^{\circ} \mathrm{C}$ ) is shown to decrease by 10 to 49 days per year. A reduction in heating degree days, of $11-32 \%$ between $1.5{ }^{\circ} \mathrm{C}$ and $4{ }^{\circ} \mathrm{C}$ of warming, is projected. Levels of daily rainfall, which currently relate to increased risk of river flooding, are shown to increase across the country, with increases of days with high impact levels of rainfall occurring by 1 to 8 days per year between $1.5{ }^{\circ} \mathrm{C}$ and $4{ }^{\circ} \mathrm{C}$ of warming. Average drought severity is projected to increase for 3-, 6-, 12- and 36-monthlong droughts. The largest changes in the severity of the 12-month drought are between -3 and $+19 \%$ between $1.5^{\circ} \mathrm{C}$ and $4{ }^{\circ} \mathrm{C}$ of warming and for 36-month drought between -2 and $+54 \%$ between $1.5{ }^{\circ} \mathrm{C}$ and $4{ }^{\circ} \mathrm{C}$ of warming. The projected future changes in high impact weather from this study will enable the characterization of climate risks and ultimately be able to better inform adaptation planning in different sectors to support the increase in resilience of the UK to future climate variability and change.
\end{abstract}

Keywords Climate impacts · Adaptation $\cdot$ Resilience $\cdot$ Climate change $\cdot$ Global warming . Extremes

Helen M. Hanlon

helen.hanlon@metoffice.gov.uk

Extended author information available on the last page of the article 


\section{Introduction}

Human and natural systems can be vulnerable to weather and climate variability, and it is clear that extreme weather events can cause impacts across many sectors in the UK. The UK is now experiencing a change in these impacts due to its changing climate. The top ten warmest years since 1884 have all occurred since 2002, with decreasing numbers of frost and icing days, increasing average temperatures, reductions in heating degree days and increases in cooling degree days and growing degree days (Kendon et al. 2020; Met Office 2018). As the climate continues to change in response to anthropogenic activities, the UK will be subject to climate hazards of different frequency, severity and duration.

Attribution studies have shown that UK heatwaves, such as that of summer 2018, could be 30 times more likely due to anthropogenic activities (McCarthy et al. 2019). Results from the latest set of climate projections for the UK (Lowe et al. 2018) estimate that summers like 2018 could be "more common than not" by the mid-twenty-first century. To illustrate the severity of this particular extreme event, summer 2018 saw a hot, dry spell in June and July 2018 which resulted in a range of heat-related impacts due to high daytime temperatures:

- Throughout the period, there was a strain on ambulance and health services. The Office of National Statistics reported a sharp increase in the daily death count coinciding with exceptionally high temperatures experienced on the 26th and 27th of July (ONS 2018).

- Police forces reported record numbers of emergency calls and an increase in violent crime (source: BBC). ${ }^{1}$

- On the hottest days, there were also transport-related problems. Specifically, melting road surfaces requiring gritting, speed restrictions were enforced on many rail lines due to the risk of rail buckling and signalling problems, and Eurotunnel services were subject to delay due to air conditioning issues (source: ITV). ${ }^{2}$

- Many water companies implemented drought plan actions to meet increased demand for water during already extremely dry months (Water UK 2018).

These impacts are becoming more common in the UK. Mortality is linked to high daytime temperatures (Gosling et al. 2007) and high night-time temperatures (Murage et al. 2017). There is a higher risk of transport disruption, which is expected to increase with climate change (Palin et al. 2013; CCC 2017). Also, there is a link between extreme temperatures and changes to human behaviour leading to increased violent crime (Field 1992; Horrocks and Menclova 2011; Mares 2013; Ranson 2014; Stevens et al. 2019; Xu et al. 2020).

The UK is not only vulnerable to warm, dry summers, it is also strongly impacted by high rainfall events, which cause widespread flooding, danger to life from fast-flowing/deep water, extensive building/structural damage, widespread and long-lasting travel disruption including dangerous driving conditions due to spray and standing water and prolonged disruption to or loss of utilities and services (CCC 2017). An example is late November 2012, when the UK experienced a sequence of heavy rainfall events that resulted in one of the wettest weeks in England seen in 50 years. The rapid succession of rainfall events and already saturated ground resulted in rapid runoff that caused severe widespread flooding leading to failure of critical

\footnotetext{
${ }^{1}$ https://www.bbc.co.uk/news/uk-44821796

${ }^{2}$ https:/www.itv.com/news/2018-07-27/transport-disruption-as-eurotunnel-roads-and-rail-hit-by-hot-weather/
} 
transport infrastructure (Jaroszweski et al. 2015), $£ 400$ million worth of damage, and affecting more than 8000 properties (source: ABI). ${ }^{3}$

New information on present-day and future weather and climate is provided by the latest set of climate projections for the UK using a range of climate models and approaches (Lowe et al. 2018). In this study, we use the UKCP 12-km resolution regional climate model projections to examine future changes in weather-related impacts rather than global model results - because the higher resolution typically provides a better representation of climate extremes (Murphy et al. 2018). Jacob et al. (2014), Dosio (2016), Moemken et al. (2018), and Spinoni et al. (2018) studied projections based on temperature, rainfall, and wind with EURO-CORDEX high-resolution regional climate models which are run at similar resolution $(12.5 \mathrm{~km})$ to those which we use from UKCP. Lower-resolution PRUDENCE regional climate models have also been used to study precipitation extremes relevant to river flooding (Fowler and Wilby 2010). These studies all consider projections for specific future periods. In contrast, here we study changes in UK climate impacts calculated at different levels of global mean temperature change, specifically $1.5^{\circ} \mathrm{C}, 2{ }^{\circ} \mathrm{C}, 2.5^{\circ} \mathrm{C}, 3{ }^{\circ} \mathrm{C}$ and $4{ }^{\circ} \mathrm{C}$ above pre-industrial temperatures, rather than over time. This is a similar approach to that adopted by Kjellström et al. (2018) which studied climate change in multiple European regional climate models at different warming levels. We adopt a time-shifting approach at $0.5{ }^{\circ} \mathrm{C}$ increments as used by Schleussner et al. (2016) and Gohar et al. (2017) and discussed in James et al. (2017) by extracting 21-year periods centred on each warming level. These warming levels are all plausible this century but do depend on the emissions scenario and the Earth's climate sensitivity (Table 1). We did not use the UKCP 2.2-km results (Kendon et al. 2019) because the current set is only available for specific time-slices that do not map onto specific levels of warming.

Here, we assess a variety of hazards through three different types of metrics. The metrics included in this study (Table 2) have been chosen to relate to flooding and severe weather risks highlighted in the National Risk Register (HM Government 2020). It should be noted that metrics included here are those for which scientifically credible methodology and data currently exist. They should not be considered as a comprehensive assessment of all changing hazards in the UK.

The first type of climate impact metrics is temperature-based, linked to changes in climatic stresses in the UK, and calculated using indicators defined by the World Climate Research Programme and World Meteorological Organization expert team on climate change detection and indices (ETCCDI). These have been previously examined in the extremes supplement of the Met Office's State of the UK Climate report (Met Office 2018).

The second type are different versions of the drought severity index (DSI), a rainfall-deficitbased metric ideal for looking at the frequency of long-term droughts. This index is computed with rainfall deficits accumulating over 3-month, 6-month, 12-month and 36-month periods. We compute DSI over a range of timescales to cover a range of differing impacts due to drought length and type, e.g. meteorological, hydrological and agricultural droughts (Mishra and Singh 2010; Cook et al. 2017).

The final type are regionally varying thresholds to identify hazards that relate to different levels of weather impact, as defined by the Met Office's National Severe Weather Warning Service (NSWWS) criteria. Operational warnings are issued when severe weather has the potential to impact the UK and are based on a combination of the likelihood and severity of the

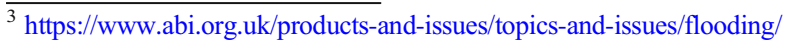


Table 1 Dates for reaching warming levels determined from the UKCP18 probabilistic projections for each emissions scenario at the 90th, 50th and 10th percentile of the global temperature distribution. A warming level not reached by the end of the projection, 2100 , is indicated with a "-", but this does not guarantee that this level of warming would not be reached if the scenarios and projections were extended further into the future

\begin{tabular}{|c|c|c|c|c|c|c|c|c|c|c|c|c|}
\hline \multirow[t]{3}{*}{ Emission scenario } & \multicolumn{12}{|c|}{ Global warming level } \\
\hline & \multicolumn{3}{|c|}{$1.5^{\circ} \mathrm{C}$} & \multicolumn{3}{|c|}{$2.0^{\circ} \mathrm{C}$} & \multicolumn{3}{|c|}{$3.0^{\circ} \mathrm{C}$} & \multicolumn{3}{|c|}{$4.0^{\circ} \mathrm{C}$} \\
\hline & 90th & 50 th & 10th & 90th & 50 th & 10th & 90th & 50th & 10th & 90th & 50 th & 10th \\
\hline $\mathrm{RCP} 2.6$ & 2020 & 2037 & - & 2037 & - & - & - & - & - & - & - & - \\
\hline $\mathrm{RCP} 4.5$ & 2020 & 2036 & 2060 & 2036 & 2056 & 2083 & 2066 & 2095 & - & - & - & - \\
\hline RCP6.0 & 2021 & 2040 & 2062 & 2041 & 2059 & 2075 & 2067 & 2082 & - & 2085 & - & - \\
\hline RCP8.5 & 2020 & 2029 & 2044 & 2031 & 2043 & 2059 & 2050 & 2064 & 2080 & 2065 & 2081 & - \\
\hline
\end{tabular}

impact occurring. The likelihood aspect relates to the certainty of the forecast and so changes with forecast lead time. The severity is based on the historical link between severe weather and its impacts in different parts of the country. Thresholds for heavy rainfall having an impact vary geographically, reflecting the variations in both the exposure of populations and

Table 2 List of impact indices studied

\begin{tabular}{|c|c|c|}
\hline Index & Threshold & Impact relevance \\
\hline Frost days & Daily minimum temperature below $0{ }^{\circ} \mathrm{C}$ & $\begin{array}{l}\text { Cold weather disruption due to higher } \\
\text { than normal chance of ice and snow }\end{array}$ \\
\hline Icing days & Daily maximum temperature below $0^{\circ} \mathrm{C}$ & $\begin{array}{l}\text { More extreme than frost days, so more } \\
\text { severe cold weather impacts }\end{array}$ \\
\hline Tropical nights & Daily minimum temperature above $20^{\circ} \mathrm{C}$ & $\begin{array}{l}\text { Health impact due to high night-time } \\
\text { temperatures with potential for heat } \\
\text { stress. Vulnerable people at increased } \\
\text { risk of hospital admission or death }\end{array}$ \\
\hline Summer days & Daily maximum temperature above $25^{\circ} \mathrm{C}$ & $\begin{array}{l}\text { High daytime temperatures with health } \\
\text { impacts for vulnerable people at risk } \\
\text { of hospital admission or death. } \\
\text { Transport disruption - e.g. track } \\
\text { buckling on railways }\end{array}$ \\
\hline $\begin{array}{l}\text { Rainfall meeting National } \\
\text { Severe Weather Warning } \\
\text { Service (NSWWS) } \\
\text { criteria }\end{array}$ & $\begin{array}{l}\text { Thresholds, which vary regionally, and } \\
\text { is applied as proxy for } \\
\text { low/medium/high impacts }\end{array}$ & $\begin{array}{l}\text { Informative for estimating periods of } \\
\text { increased risk of river flooding } \\
\text { (fluvial flooding only). Note these } \\
\text { are not appropriate for assessing } \\
\text { pluvial flooding (surface water } \\
\text { flooding) }\end{array}$ \\
\hline Drought severity index & $\begin{array}{l}\text { This index is not threshold based. } \\
\text { Instead, it is calculated with 3-, 6-, } \\
\text { 12- and 36-month rainfall deficits } \\
\text { provided as a percentage of the mean } \\
\text { annual climatological total rainfall } \\
\text { (1981-2000) }\end{array}$ & $\begin{array}{l}\text { The impacts of the differing length of } \\
\text { rainfall deficits vary regionally due to } \\
\text { variation in vulnerability. Depending } \\
\text { on the level of vulnerability to } \\
\text { reduced rainfall, rainfall deficits } \\
\text { accumulated over } 3,6,12 \text { and } \\
36 \text { months measured by these indices } \\
\text { could lead to meteorological, } \\
\text { agricultural and hydrological drought }\end{array}$ \\
\hline Growing degree days & Daily mean temperature above $5.5^{\circ} \mathrm{C}$ & $\begin{array}{l}\text { Energy available for plant growth over a } \\
\text { year. Not a measure of season length }\end{array}$ \\
\hline Heating degree days & Daily mean temperature below $15.5^{\circ} \mathrm{C}$ & Indicator of energy demand for heating \\
\hline Cooling degree days & Daily mean temperature above $22{ }^{\circ} \mathrm{C}$ & Indicator of energy demand for cooling \\
\hline
\end{tabular}


infrastructure, as well as the vulnerability of natural and human systems to infrequent conditions. These warnings are based on the likelihood of impacts occurring anywhere within a region. So these metrics are calculated as counts of days where these thresholds are exceeded at any gridbox within the region and therefore can be used as a proxy for issuing of weather warnings. Daily rainfall is used to inform the NSWWS on the possibility of river flooding. Other thresholds, based on 3-hourly rainfall are used to alert forecasters to possible surface flooding, but we have not included them in this study. Such high-frequency events are likely better assessed with simulations offering high enough resolution to be able to resolve the finergrained dynamics of convective (typically summer) storm systems - for example, exceedance of 30 - and $100-\mathrm{mm} / \mathrm{h}$ rainfall rates studied with the UKCP Local 2.2-km simulations (Kendon et al. 2014; Kendon et al. 2019). While these thresholds relate to the NSWWS, the decision to issue a warning is based on a combination of factors, including exceedance of these thresholds, as judged by Met Office forecasters.

\section{Method}

\subsection{Calculating impact-relevant metrics}

The climate impact metrics of specific relevance to UK adaptation (Table 2) have been computed with UKCP 12-km simulations covering the UK. These metrics involve calculation of exceedances of specific thresholds, beyond which impacts from the climate hazard are expected, except for drought metrics which are based on accumulations of rainfall deficits over long periods. Across the threshold-based metrics associated with different hazards - relating to human health, energy demand and agriculture - the same threshold values are used for future indices, assuming exposure and vulnerability do not change in future.

\subsubsection{Temperature-based climate impact metrics (including ETCCDI)}

Frost days, icing days, tropical nights and summer days are all an annual count of days per year where the daily variable is either above or below that threshold (Table 3 ). They do not measure by how much that threshold is exceeded; a day at $-10{ }^{\circ} \mathrm{C}$ contributes the same amount to the annual frost day value as a day at $-1{ }^{\circ} \mathrm{C}$. As such these indices are a measure of the frequency of occurrence of potential associated impacts, though not the severity of the associated impacts. The metrics used here are also used in the annually published "State of the UK Climate Report" (Kendon et al. 2020; Met Office 2018).

The degree day indices used for inferring energy demand and growing season are the cumulative sum of all degrees above a threshold each day, added up over the whole year. The index is given in "degree days", a unit that should be considered as a measure of both frequency of occurrence and quantity.

The Met Office National Climate Information Centre approach, which produces the "State of the UK Climate" reports, uses daily mean temperature (i.e. for degree day indices) calculated from observations of mean daily minimum and daily maximum temperatures, as observations of daily means are not available. We replicate this approach with the regional climate model (RCM) data to match their methodology. 
Table 3 Details of thresholds used in this report taken from State of the UK Climate reports (Kendon et al. 2019)

\begin{tabular}{|c|c|c|c|}
\hline Index & Variable & Threshold & Count \\
\hline Frost days & Daily minimum temperature & $<0{ }^{\circ} \mathrm{C}$ & Days below this threshold \\
\hline Icing days & Daily maximum temperature & $<0{ }^{\circ} \mathrm{C}$ & Days below this threshold \\
\hline Tropical nights & Daily minimum temperature & $>20^{\circ} \mathrm{C}$ & Days above this threshold \\
\hline Summer days & Daily maximum temperature & $>25^{\circ} \mathrm{C}$ & Days above this threshold \\
\hline Growing degree days & Daily mean temperature & $>5.5^{\circ} \mathrm{C}$ & $\begin{array}{l}\text { Degrees above this threshold per day } \\
\text { accumulated over each year }\end{array}$ \\
\hline Heating degree days & Daily mean temperature & $<15.5^{\circ} \mathrm{C}$ & $\begin{array}{l}\text { Degrees below this threshold per day } \\
\text { accumulated over each year }\end{array}$ \\
\hline Cooling degree days & Daily mean temperature & $>22{ }^{\circ} \mathrm{C}$ & $\begin{array}{l}\text { Degrees above this threshold per day } \\
\text { accumulated over each year }\end{array}$ \\
\hline
\end{tabular}

These indices are computed with the UKCP 12-km data to produce maps shown in Fig. 2 and Fig. 3. Regional averages are then taken for England, Scotland, Northern Ireland and Wales (see Supplement Section 3 for regional averages). Unlike the indices based on the National Severe Weather Warning Service thresholds, the threshold values for these indices are the same across all UK regions.

\subsubsection{Drought metrics}

The drought severity index (DSI) is a rainfall-based drought index based on an $n$-month $(n=3,6,12$ or 36$)$ precipitation accumulation concept, originally introduced in Bryant et al. (1992), and termination rule, as in Phillips and McGregor (1998). Monthly rainfall deficits are calculated for each month as an anomaly compared to the 1981-2000 monthly climatology. For each month, on a rolling basis, the monthly anomaly and the preceding $n-1$ month anomalies are summed to give an $n$-month total. If the accumulated anomaly of the $n$-month period is negative, this is the value of the DSI metric for that month; otherwise, the DSI for that month is zero. We calculate the DSI metric separately for each grid box because each location's resilience to drought will vary greatly due to land type and land use in those locations, and impacts for a given deficit (in $\mathrm{mm}$ ) vary greatly for different locations. The DSI is also standardized by the mean annual total climatological rainfall (1981-2000) for each grid box individually. Consequently, DSI is provided as a percentage of the mean annual total rainfall and can be thought of as a measure of severity of water shortage as it is the factor by which the shortfall of rainfall compares to the climatological annual amount.

As it is based on the accumulation of deficit, DSI is good for assessing the severity of droughts, but is not a measure of frequency. The standardized precipitation index (SPI) is often used to measure drought and is similar to DSI in that it only uses rainfall data but fits statistical distributions rather than using accumulated deficits. We chose DSI as it has previously been used to study future drought scenarios, with RCMs, specifically for the UK by Rahiz and New (2013) and Blenkinsop and Fowler (2007). A 3-, 6-, 12- and 36month DSI is computed with the UKCP 12-km data to produce maps shown in Fig. 4. Regional averages are then taken for England, Scotland, Northern Ireland and Wales. 


\subsubsection{NSWWS metrics}

These indices are proxies for "low", "medium" and "high" impacts from daily total rainfall. They are based on regionally varying thresholds based on rainfall meeting the NSWWS criteria. The thresholds are those designed for an automated "first guess" system, which is available as part of the guidance to forecasters in determining if a warning should be issued. Each metric's thresholds (Table 4) are defined for a set of regions in the UK (SupplementTable1), reflecting the potential for impact.

NSWWS warnings, in practice, use the estimated likelihood of exceeding one of these thresholds combined with an expert judgement that takes into account the recent preceding weather (e.g. is the ground already frozen or saturated) and if the events are happening at a time when exposure is higher (e.g. days with higher than normal travel). For this project, we acknowledge that the application of the level of subjective expert judgement applied to each NSWWS warning would not be viable in the analysis of 12 different 100-year simulations, and so we report only on the automated threshold-based part of this approach and explore the relative hazards at different levels of global temperature rise.

Metrics indicating potential impacts from river flooding are based on 24-h precipitation totals. As NSWWS differentiates between saturated and unsaturated ground, but soil saturation data was not available from UKCP for this analysis, we assume the ground is saturated. In practice, this will lead to an overestimate of the absolute number of occurrences but will still be illustrative of the relative changes that occur at increasing levels of global mean temperature.

For each case, the frequency of passing thresholds is reported as the average number of days per year when the threshold is passed somewhere in a region, which is intended to estimate the issuing of severe weather warnings. This also means that the geographical extent of an area affects how often a threshold is passed, with larger regions more likely to pass a threshold on any given day.

\subsection{Data}

\subsubsection{Model projections}

The model projections consist of an ensemble of 12 RCMs driven at their boundaries by global simulations (60-km resolution) of the Met Office's HadGEM3 model (version GC3.05). The RCM projections (Murphy et al. 2018) have a resolution of $12 \mathrm{~km}$, comparable to that of the EURO-CORDEX data (Jacob et al. 2014). The regional models capture model uncertainty using a perturbed parameter approach (both in their own model parameters and that of the

Table 4 Thresholds based on the Met Office National Severe Weather Warning Service criteria. Regional definitions are provided in Supplement Table 1

\begin{tabular}{lllll}
\hline Index & Regions & Low & Medium & High \\
\hline 24-h precipitation & England and Wales & $\geq 25 \mathrm{~mm}$ & $\geq 50 \mathrm{~mm}$ & $\geq 80 \mathrm{~mm}$ \\
24-h precipitation & Northern Ireland & $\geq 25 \mathrm{~mm}$ & $\geq 50 \mathrm{~mm}$ & $\geq 80 \mathrm{~mm}$ \\
24-h precipitation & NW Scotland & $\geq 50 \mathrm{~mm}$ & $\geq 70 \mathrm{~mm}$ & $\geq 80 \mathrm{~mm}$ \\
24-h precipitation & SW Scotland & $\geq 50 \mathrm{~mm}$ & $\geq 60 \mathrm{~mm}$ & $\geq 65 \mathrm{~mm}$ \\
24-h precipitation & South and East Scotland & $\geq 30 \mathrm{~mm}$ & $\geq 45 \mathrm{~mm}$ & $\geq 55 \mathrm{~mm}$ \\
24-h precipitation & NE Scotland & $\geq 45 \mathrm{~mm}$ & $\geq 60 \mathrm{~mm}$ & $\geq 75 \mathrm{~mm}$ \\
\hline
\end{tabular}


parameters in the driving global model) and contain uncertainty from natural variability. Evaluation has shown that the $12-\mathrm{km}$ RCM is better able to simulate more extreme daily rainfall events, especially in winter, compared to the global model which underestimates extreme rainfall frequency in the UK (Murphy et al. 2018).

Downscaled 12-km projections were only produced for one future scenario (RCP8.5) for UKCP owing to the computational expense of running these simulations. UKCP also developed a technique to derive projections for other scenarios from the projections of RCP8.5 although this approach has only been applied to the 60-km projections (Gohar et al. 2018), and so this "derived projection" product is not used here.

These downscaled projections are driven with 12 variants of the HadGEM3-GC3.05 global climate model, which tend to sample the warmer end of the future global warming response range projected by the full set of UKCP global projections (Murphy et al. 2018) which includes HadGEM3-GC3.05 and CMIP5 models. This is consistent with recent research showing that HadGEM3-GC3.05 has an equilibrium climate sensitivity (global warming response to doubling carbon dioxide in the atmosphere relative to pre-industrial concentrations) greater than the current Intergovernmental Panel on Climate Change (IPCC) range and the CMIP5 set of models. This might be problematic if we were using the $12-\mathrm{km}$ results to look at the time taken to reach a given warming level. However, we reduce the impact of this effect by considering only the response at a given warming level.

To consider model projections in terms of warming level rather than time, our first step is to use the global simulations to identify the time when the global mean temperature reaches different levels of warming, i.e. $1.5^{\circ} \mathrm{C}, 2{ }^{\circ} \mathrm{C}, 2.5^{\circ} \mathrm{C}, 3{ }^{\circ} \mathrm{C}$ and $4{ }^{\circ} \mathrm{C}$, (where $0{ }^{\circ} \mathrm{C}$ warming is defined as the global mean temperature for 1850-1900, otherwise referred to as "pre-industrial"). The period 1850-1900 is not the true pre-industrial state, but it is the earliest time for which worldwide observations are considered extensive enough and reliable enough to provide a baseline for estimates of the global mean temperature anomaly. It is known that this is likely to be slightly warmer than the true pre-industrial state, but the amount of this additional warming is generally considered too uncertain to be included in warming estimates. This is in line with the approach of IPCC (IPCC 2018) and UKCP (Gohar et al. 2017). The year when a given level of warming is reached is found individually for each global model simulation (which drove each regional model simulation) from a moving 21-year mean of global temperature anomaly. This year is then used as the central estimate for defining the future period where that level is possible (Supplement Table 2). To account for uncertainty in the timing of reaching a given warming level, we take 10 years on either side of this central estimate and extract a 21-year period from each RCM simulation. This is used to calculate the metrics, and the time mean of these provides an estimate of what the metric value will be at a given warming level. Global mean warming levels used for the global models are calculated with the same method as Gohar et al. 2017, an anomaly from "present-day" (defined here as 1981-2000) and the observational warming from "pre-industrial" (defined here as 1850-1900) is added to present-day warming level calculated from HadCRUTv4 which is $0.51{ }^{\circ} \mathrm{C}$. This approach reduces the model spread in present-day temperatures and ensures agreement with time-mean observations during this period.

\subsubsection{Observations}

Gridded 12-km UK land observations released as part of UKCP (Lowe et al. 2018) are used throughout this study. In UKCP three alternative baseline periods were used as these were all 
commonly used and requested by the user community. In this study, the impact metrics are calculated from observations for all three baseline periods to show how they have changed with observed warming. These periods are 1961-1990, 1981-2000 and 2000-2017. The 1981-2000 period, also used in UKCP as RCM simulations start in 1980, is the model baseline reference period which is used to bias adjust the RCM (from here on referred to as "calibration period").

\subsubsection{Bias adjustment}

To minimize systematic differences between model results and observations, the RCM results are bias-adjusted against present day (1981-2000) using the approach of Scaled Distributions Mapping (Switanek et al. 2017). Conceptually similar to quantile delta mapping (Cannon et al. 2015), this adjusts the distribution of daily precipitation or temperature against observations while preserving the climate trend and, in the case of rainfall, accounts for the number of "dry days" in observations. This is performed separately for each 21 -year time slice for the future warming periods adjusting each to the 1981-2000 baseline calibration period. The analysis shows that the metrics calculated from the bias-adjusted RCM agree well with the metrics calculated with observations (see Supplement Section 1 for more details).

\section{Results}

Figure 1 shows how the impact metrics are projected to change on average for the whole UK. Cold weather impacts described by frost days, icing days and heating degree days are all projected to decrease. Hot weather impacts, described by summer days, tropical nights, cooling degree days and growing degree days, are all projected to increase. Also, droughts of 3-, 6-, 12- and 36-month duration are projected to increase in severity. These metrics were analysed for each UK region, England, Northern Ireland, Scotland and Wales, taking the mean average of all grid boxes in those regions. For different regions, the projections all showed a similar direction of change, but the magnitude of the changes did vary for different regions. See the figures in Supplement Section 3 for more details.

Heavy rainfall events (Fig. 5) are also projected to increase in frequency with global warming level, the magnitude of which varies for different regions.

\subsection{Temperature impact metrics}

\subsubsection{Cold weather impacts}

Frost days, where the minimum daily temperature is below $0{ }^{\circ} \mathrm{C}$, have large negative impacts on crops (Barlow et al. 2015), transportation (Jaroszweski et al. 2014) and energy demand (Wood et al. 2015). Kendon et al. (2020) and Met Office (2018) note an observed drop in the frequency of frost days over recent decades, and our results indicate that all parts of the UK are projected to continue to experience a reduction in frost days as global warming increases (Fig. 2, top row).

Figure 2 (upper row) shows maps of the median (from the RCM ensemble) number of frost days for each level of global mean warming and observational 1981-2000 mean. While there is a general reduction in frost days across the country, different administrative regions of the UK show a variation in the magnitude of the projected decrease in the numbers of frost days. There 

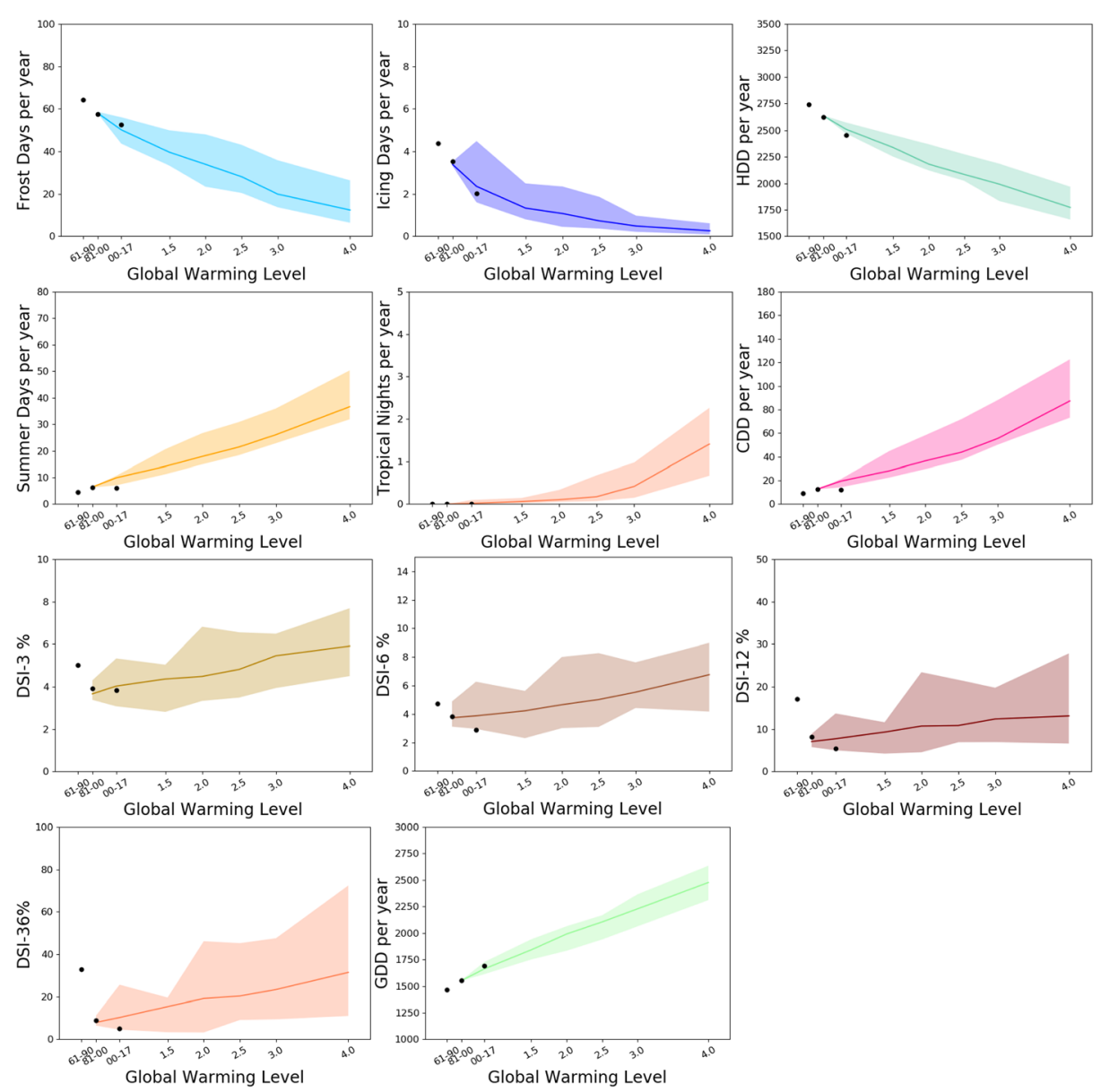

Fig. 1 Evolution of each impact index (described in Table 2) with increasing global mean temperature averaged over the UK. This is the 21-year mean average index centred on the year each warming level is predicted to be reached. The ensemble range is shown as a plume with the ensemble median average (solid line). The mean average index is computed with observations for baseline periods 1961-1990, 1981-2000 and 2000-2017 (black dots)

is a steady rate of decrease in frost days per year with global mean warming in all UK regions; see Supplement Figure 5. In all regions, there is a reduction, but the absolute reductions are largest in Scotland, where frost days are currently higher than in other regions - suggesting Scotland may benefit more from this change in terms of the reductions in cold weather impacts.

An icing day is a separate metric, which is similar to frost days, but measures more severe cold weather impacts as it is defined as a day where the maximum daily temperature is below $0{ }^{\circ} \mathrm{C}$. In other words, the temperature does not rise above $0{ }^{\circ} \mathrm{C}$ for the whole day. By definition, the daily minimum will also be below $0{ }^{\circ} \mathrm{C}$ so all icing days are also counted as frost days. On an icing day, more ice will form, having a greater impact than other frost days. With an increase in global warming, a reduction in icing days is expected across the UK Fig. 2 (middle row).

There is a sharper decrease in icing days at lower warming levels than at higher warming levels, as its value tends toward zero (Fig. 1). This is slightly different from 


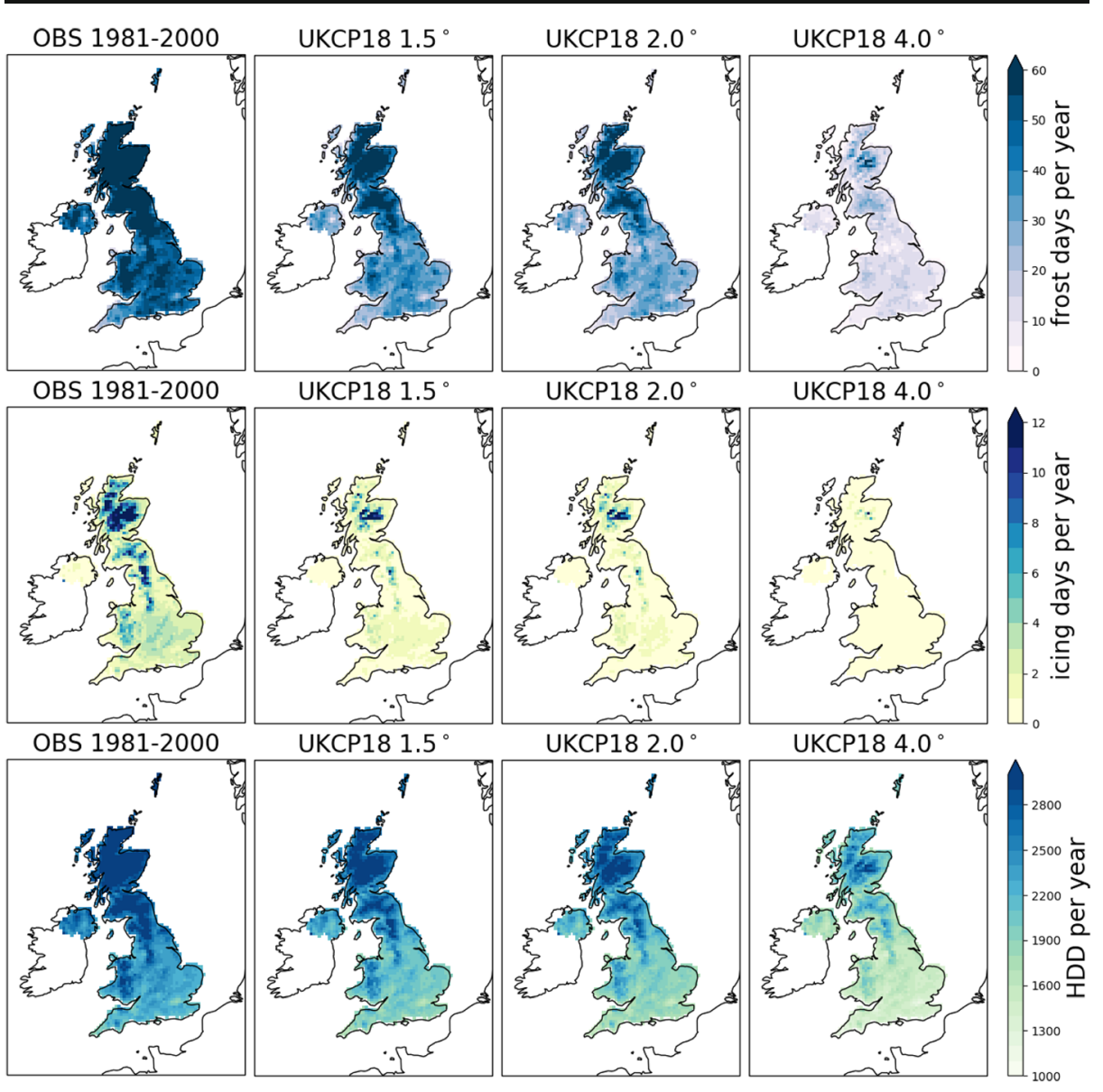

Fig. 2 Maps of median values of cold weather impact metrics (frost days, icing days and HDD) per year. Observations for the baseline period (1981-2000) and model projections at $1.5^{\circ} \mathrm{C}, 2{ }^{\circ} \mathrm{C}$ and $4{ }^{\circ} \mathrm{C}$ of global mean warming. Values at future warming levels are calculated as 21 -year average indices centred on the year each warming level is projected to be reached

the more frequent and less severe frost days that show a more linear decrease with increasing warming level. As the global warming level approaches $4{ }^{\circ} \mathrm{C}$, the icing days index decreases to 0 in all UK regions (see Supplement Figure 6). This does not mean there would no longer be any icing days occurring in the UK, but it is more likely the UK could have some milder winters without any icing days, which is currently a rare occurrence.

The metric heating degree days (HDD) is calculated as the daily mean temperature in degrees below $15.5{ }^{\circ} \mathrm{C}$ every day added up over the whole year. It is related to power consumption for heating required on cold days (Met Office 2018). Hence, this index is useful for predicting future changes in energy demand for heating. Figure 2 (lower row) shows that as the global temperature increases, temperatures fall below this threshold less often and HDD decreases throughout the UK. In all regions, a reduction in heating degree days is seen (see Supplement Figure7) which suggests a possible societal benefit of reducing heating costs and winter energy demand. 
The number of frost days, number of icing days and HDD are projected to decrease across the UK, but the magnitude of the decrease varies for the different regions (Supplement Figs. 5 to 7). All regions show a reduction, but absolute reductions are the largest in Scotland. So, as the climate warms, the UK can expect reduced hazards due to cold weather and reduced heating costs. There may also be some negative effects on sectors that benefit from cold winter conditions, such as winter tourism. However, future UK winter climate will still be variable year to year, so severe cold winters are still likely to occur - just less often - so it is important to remain resilient to severe winters when they do occur.

\subsubsection{Hot weather impacts}

Summer days and tropical nights are measures of the health impact from high temperatures and heatwaves as they are based on temperature thresholds which, when exceeded, can pose risks to human health and wellbeing (Met Office 2018; Arbuthnott and Hajat 2017; Basu 2009; Murage et al. 2017).

A summer day is defined as a day where the maximum daily temperature exceeds $25^{\circ} \mathrm{C}$. These are shown to increase everywhere throughout the UK (Fig. 3 upper row). There is a higher frequency in the South of the UK, and this is projected to increase considerably with global warming.

For different regions, shown in Supplement Figure 8, England has the highest frequency of summer days already, and the projections show England to also have the largest increase with global warming level. This is followed by Wales which also shows large increases. Northern Ireland and Scotland have a relatively low frequency for this threshold being exceeded on average when compared to other UK regions. However, as projections show frequency increasing, by $4^{\circ} \mathrm{C}$ warming, Northern Ireland and Scotland will experience similar numbers of summer days to that of England currently. With this increase in frequency, and because most of these will cluster during the summer months, future summers are projected to become hotter, and adaptation will be more important.

Tropical nights is an index used for measuring how many extremely warm nights occur; it is relevant for human health because in periods of high daytime temperatures, it is important that the body has time to recover from the heat stress of the daytime during the lower temperatures at night. It is defined as the number of days per year; the daily minimum temperature is above $20{ }^{\circ} \mathrm{C}$.

Figure 3 (second row) shows this threshold is only exceeded rarely and mainly in major UK cities, particularly London. This is mainly due to urban heat island effects and exacerbating temperatures in major cities. Scotland and Northern Ireland only very rarely see exceedance of this threshold. It should be noted that without examples in the present climate, it is not possible to validate this metric as effectively as the other metrics. While tropical nights are rare in the current UK climate, as global warming increases, models project an increase in the number of tropical nights on average for the UK (Fig. 1). Projections for all administrative regions of the UK show a rise in their occurrence with global temperature. The rate of increase grows at higher levels of warming, as will the associated health impacts, especially in urban areas and the south, if unmitigated.

The metric cooling degree days (CDD) is calculated in the same way as heating degree days, but in this case, it is the annual sum of the number of degrees; the daily mean temperature is above $22{ }^{\circ} \mathrm{C}$ each day. It is related to power consumption for cooling systems and air conditioning required on hot days, so this index is useful for predicting future changes in 


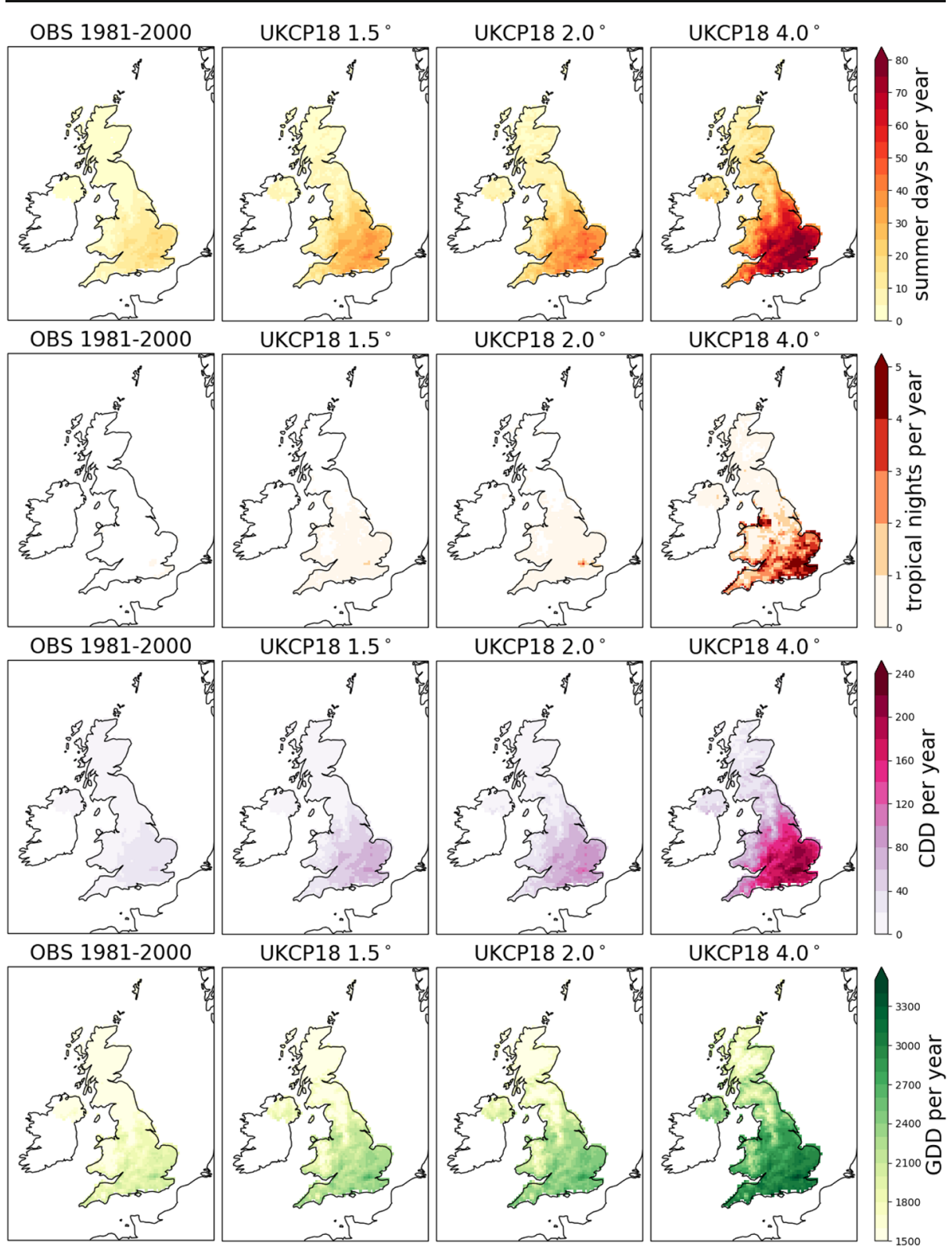

Fig. 3 Maps of median values of hot weather impact metrics (summer days, tropical nights, GDD and CDD) per year. Observations for the baseline period (1981-2000) and model projections at $1.5^{\circ} \mathrm{C}, 2^{\circ} \mathrm{C}$ and $4{ }^{\circ} \mathrm{C}$ of global mean warming. Values at future warming levels are calculated as 21 -year average indices centred on the year each warming level is projected to be reached

energy demand for cooling. CDD is projected to increase in the UK (Fig. 3 third row) and across all UK regions (Supplement-Fig. 10). The largest increases are in England, particularly the Southeast (Fig. 3 third row). This increase in CDD suggests a negative societal impact of increasing power costs and summer energy demand. 
Both HDD and CDD thresholds are based on average temperature values for when household heating and cooling systems are used, respectively. In practice, this varies greatly throughout the UK, depending on personal thermal comfort levels and building designs (see Harvey (2020)), so these results should be considered as rough estimates of overall demand changes on a large scale. However, using these thresholds, comparing the relative demand for heating and cooling shown by the degree day changes, the increase in energy required for cooling should be smaller than the reduction in energy demand for heating. The seasonal change in energy demand inferred from CDD and HDD projections would present an adaptation challenge for the energy industry to meet changing levels of demand throughout a typical year. It should also be noted that heating is mainly fossil fuel based (e.g. natural gas) in the UK and emissions from heating make up 17\% of the UK total (CCC 2016) which is making low carbon heating an option for the UK to meet its emissions targets. ${ }^{4}$ Milder winters in the future may present an opportunity to reduce emissions from this sector, if the increase in cooling system usage in summer is provided by energy-efficient means and low-carbon electricity production.

Growing degree days (GDD) is the daily mean temperature exceedance in degrees above $5.5^{\circ} \mathrm{C}$ every day added up over the whole year. It is useful for measuring whether conditions are suitable for plant growth (Kendon et al. 2020; Met Office 2018). The GDD index increases throughout the UK with warming level (Fig. 1 and Fig. 3 lower row and Supplement Figure 11) suggesting potential for larger crop yields. GDD is based purely on temperature and so does not estimate the growth of specific species as it does not include any measure of rainfall/drought, sunlight, day length or wind, species vulnerability, nor does it account for plant dieback in extremely high temperatures. So, there is only a positive impact from increased GDD until temperatures reach a critical level above which there are detrimental impacts on plant physiology (Barlow et al. 2015).

\subsection{Droughts}

Droughts are extreme events with a shortage of water in specific areas. They are difficult to define universally, as several factors can cause or exacerbate them, from a shortage of rainfall to poor water management. However, they can be divided into meteorological (defined essentially on the basis of rainfall deficiency), hydrological (accumulated shortfalls in runoff or aquifer charge) and agricultural (the availability of soil water for the growing season) (Cook et al. 2017).

Even though it has just been shown that increases in heavy rainfall could be seen in a warmer climate, it is possible that the frequency of prolonged dry periods could also increase. Overall, the UK is more vulnerable to impacts from multi-season, longer duration hydrological droughts than short intense meteorological droughts. Short, intense spring/summer rainfall deficiencies can threaten water supplies in areas dependent on surface water, for example, South West England. However, deficiencies over 12 months or longer pose a greater threat, because of the failure of groundwater resources to be adequately replenished during dry winters (Cole and Marsh 2006). So here, the drought severity index (DSI) has been computed over 3 months (DSI-3), 6 months (DSI-6), 12 months (DSI-12) and 36 months (DSI-36). Figure 1 shows that the severity of droughts of each length is projected to increase in the UK, especially in the South and East of the UK (Fig. 4).

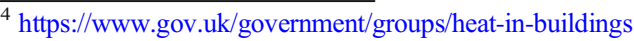


The distribution of each DSI metric for each warming level was compared to the baseline, using paired $t$ tests, to assess whether the null hypothesis of no difference between the baseline and the warming level could be rejected, using a $1 \%$ significance level. A $1 \%$ significance level was chosen as 5 warming levels were compared to the baseline, and this gives an overall

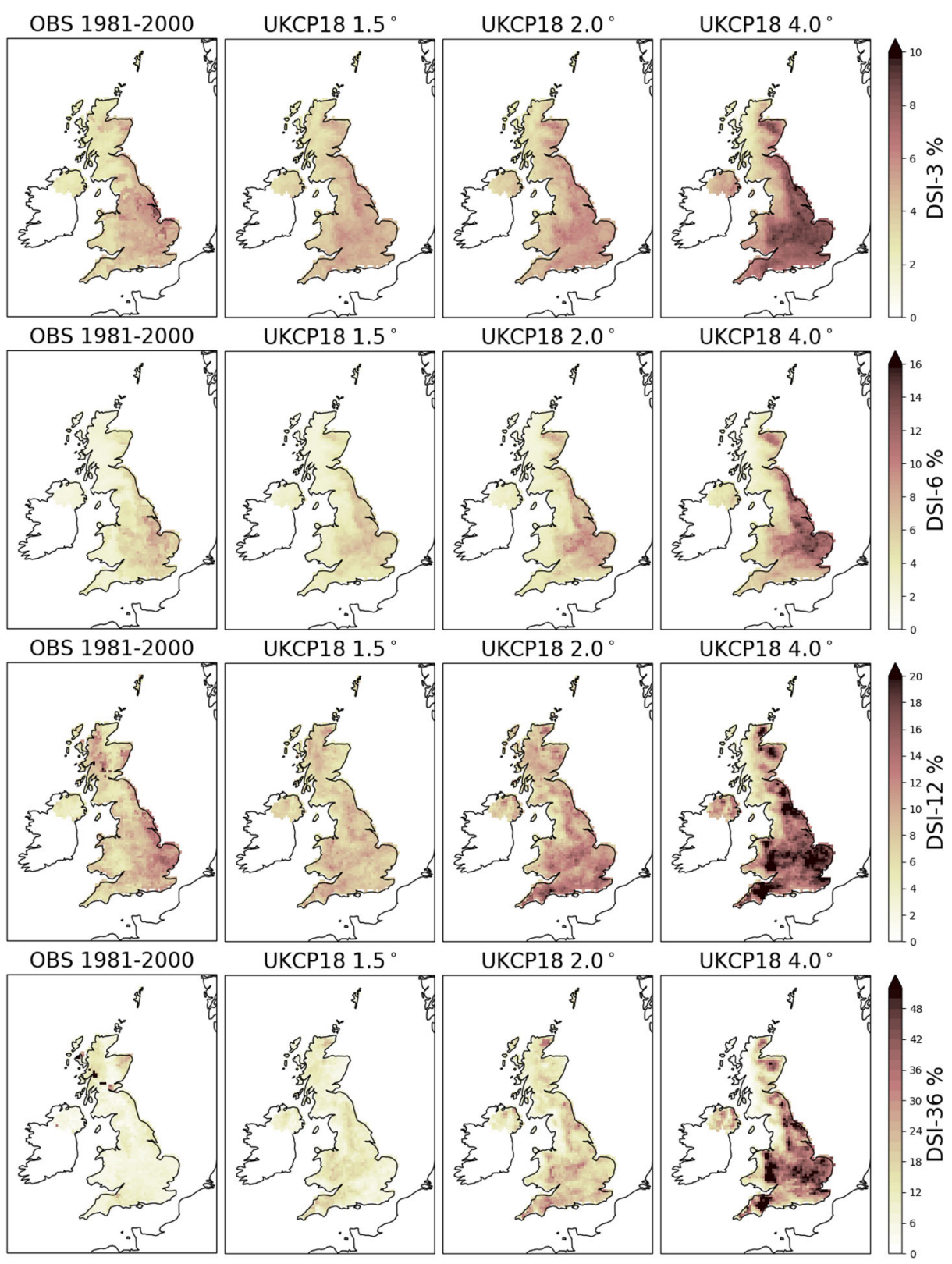

Fig. 4 Maps of median values of drought impact metrics (DSI-3, DSI-6, DSI-12 and DSI-36) per year. Observations for the baseline period (1981-2000) and the model projections at $1.5{ }^{\circ} \mathrm{C}, 2{ }^{\circ} \mathrm{C}$ and $4{ }^{\circ} \mathrm{C}$ of global mean warming. Values at future warming levels are calculated as the 21 -year average indices centred on the year each warming level is projected to be reached 
familywise error rate of 5\% across all the comparisons. For comparisons at $1.5{ }^{\circ} \mathrm{C}$ of warming, there was not enough evidence to reject the null hypothesis of no change. In summary, changes in all DSI metrics at $2{ }^{\circ} \mathrm{C}$ of warming and above are statistically significant.

Spatially, we can see a similar pattern of droughts in all length DSI metrics, with lower levels of DSI in Northern Ireland compared to the rest of the UK (Fig. 4). The drought metric spatial pattern does change with warming level, again in a consistent way across the 3-, 6-, 12and 36-month DSI, with a reduction in the North and West UK and an increase in South and East UK. This similarity is reflected in the regional averages (Supplement Figs. 12 to 15). There is an especially significant increase in the South of the UK, specifically England and Wales regions.

In Scotland, droughts appear to become less frequent in the West and more frequent in the East, particularly for the longer 12- and 36-month DSI. When averaged over the whole country, the overall change is not discernibly different to present day (see Supplement Figs.14 and 15), but this is because the changes in West to East cancel each other out. East Scotland projections show increased drought conditions in a warmer climate which may require adaptation measures.

The changes are relatively smaller in Northern Ireland than in South and East UK, but there is still a significant increase in droughts throughout the region as global warming increases.

Typically, England and Wales experience more dry spells than Scotland and Northern Ireland at present. Dry spells in England and Wales are projected to increase in severity compared to climatological annual total rainfall based on DSI-3, 6, 12 and 36.

These projected increases in drought will have an impact on water available for crop growth and therefore are an important consideration for the agricultural industry. For example, how resilient to water scarcity are the crops being grown, and will more irrigation be required to maintain these? The level of actual impact experienced also depends on water demand and management in each location, so the water industry, especially in England and Wales where projected changes are larger, may need to adapt water management practices to cope with increased levels of drought.

\subsection{Heavy rainfall metrics based on NSWWS criteria}

The heavy rainfall metrics are based on 24-h precipitation thresholds in $\mathrm{mm} /$ day which are designed to be used for identifying prolonged rainfall which may lead to river (fluvial) flooding. Projections of these metrics show increases in the moderate and high-impact heavy rainfall (Fig. 5) with global warming level, suggesting more frequent river flooding could impact the UK.

The thresholds vary regionally (see region definitions in Supplement Table 1) and by the condition of the land the rainfall lands on (e.g. already saturated or not). As land saturation information is not available from UKCP we use only the saturated thresholds. In practice, this may lead to an overestimate of the absolute number occurrences but is still illustrative of the relative changes that occur at increasing levels of global mean temperature.

For the calibration period, the frequency of exceeding a threshold at any grid cell in the projections will match that in the observations due to the adjustment process. As a result, the ETCCDI metrics for hot and cold conditions which are reported as the area average of the frequency of occurrence agree well with observations (Fig. 1). 

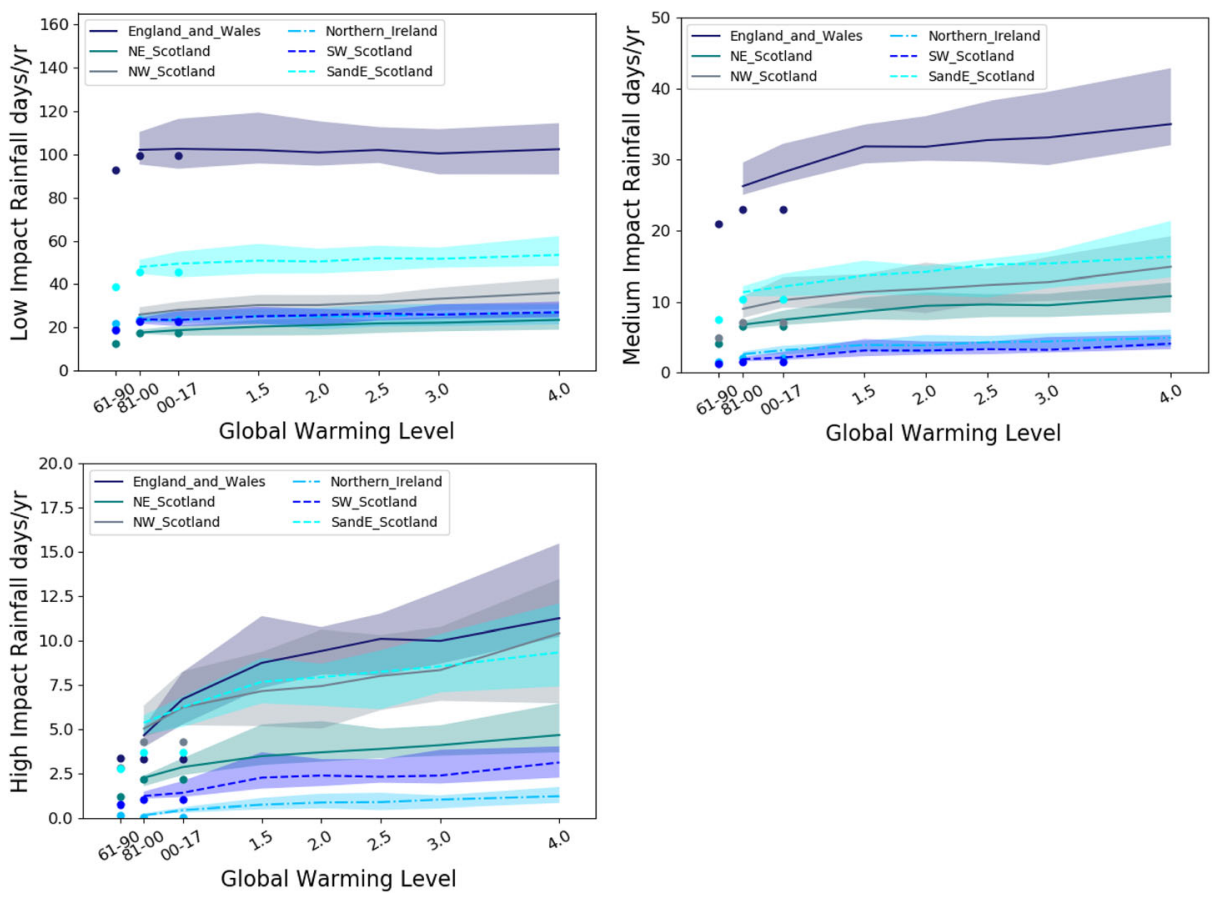

Fig. 5 Evolution of exceedance of the low, medium and high rainfall thresholds in days per year with increasing global mean temperature for each administrative area of the UK shown as separate plumes. This is the 21-year mean average index centred on the year each warming level is predicted to be reached. The ensemble range is shown as a plume with the ensemble median average (solid line). The mean average index is computed with observations for baseline periods 1961-1990, 1981-2000 and 2000-2017 (coloured dots)

For thresholds based on the NSWWS, we wish to estimate future changes in the frequency of weather warnings rather than area average frequencies. We classify a warning as to when a NSWWS threshold is exceeded anywhere within a region on a given day. This could be a single grid cell or the whole region. This means that the frequency of warnings is also dependent on the spatial extent of any threshold exceedance.

For example, if the projections were to exceed a NSWWS threshold typically in only a single grid cell at a time, the number of warnings would be relatively large but of small spatial extent for each event. Conversely, if the threshold were typically exceeded across a large area at once, the number of warnings would be far smaller but of greater spatial extent per event. Consequently, the spatial extent of exceedance would also need to agree in observations and projections if the frequency of warnings in a region for both observations and projections were to agree. This explains the discrepancy for 1981-2000 between observations and bias-adjusted projections. Figure 5 shows a higher frequency of warnings in projections, for the higher impact levels in England and Wales, Northwest Scotland, and South and east Scotland regions. The implication is that in these cases, smaller areas of exceedance are occurring more frequently than in observations. The characteristics of the spatial extent and coherency of exceedance events have not been examined in detail here but warrant further research. 


\section{Discussion and summary}

We have presented a range of impact relevant hazard metrics derived with respect to fixed global warming levels and using the new UKCP regional model dataset. The results reinforce the view from the second UK Climate Change Risk Assessment (CCC 2017) of the potential for severe impacts on the UK from changes in precipitation, leading to both flooding and drought and extremely high temperatures.

There is also some evidence that the UK could benefit from reduced cold weather-related impacts, although while reductions in travel delays, health impacts from icy conditions, and reduced demand for winter heating are positive, there may be some sectors, including winter tourism, where the changes are not beneficial.

The fact that there are changes evident at even $1.5^{\circ} \mathrm{C}$ of global warming compared to the present provides a clear reminder that even the most optimistic global emissions mitigation scenarios are likely to need to be accompanied by adaptation. However, the amount of adaptation will clearly be reduced by the reduction in emissions.

Focusing in more detail on area mean results (Fig. 1and 5), it is clear that not all impact metrics change linearly with the global warming level. This implies that the benefits from mitigation must be considered on a sectoral basis. For instance, while the reduction in the number of hot summer days continues to be experienced across the full range of global temperature levels, including a reduction in hot summer days when moving from $2{ }^{\circ} \mathrm{C}$ to $1.5^{\circ} \mathrm{C}$ of global warming, the effect on tropical nights is very different. Large reductions occur when reducing the limit on global temperatures from $4{ }^{\circ} \mathrm{C}$ to $2{ }^{\circ} \mathrm{C}$, but a much lower reduction per degree of global temperature change is experienced when going from a global warming limit of $2{ }^{\circ} \mathrm{C}$ to $1.5^{\circ} \mathrm{C}$. However, while not all the impact metrics change linearly over the $1.5{ }^{\circ} \mathrm{C}$ to $4{ }^{\circ} \mathrm{C}$ range, it is noteworthy that the majority are reasonably linear for both temperature-related and precipitation-related cases. This can be compared with the Western Europe curves in the supplementary material of Arnell et al. (2018) for the temperature-based metrics. Both sets of results show similar curvature, or lack of it, for heating and cooling degree days. Furthermore, both studies show the reduction in heating degree days and increase in cooling degree days as the global temperature increases. The upward trend in flood frequency we find for the UK is quite different to the flooding metric used by Arnell et al. (2018); however, both indicate a likely increase in the flooding for Western Europe and the UK, respectively.

The spatially varying metrics illustrate the importance of considering spatial detail in adaptation planning. Low-temperature-related metrics generally show the largest absolute change in the north of the UK (Fig. 2). This is typically because the present-day values of, for example, frost days is greater in this part of the UK than that in the south where there is much less scope for change. This is likely to be partially offset by the spatial pattern of annual or seasonal warming, which is greater in the southern UK. For high-temperature metrics, the largest changes are typically in the south of the UK, especially the southeast (Fig. 3).

The spatial variation of median projected change in heavy rainfall (Fig. 5) and drought (Fig. 4) indicates the largest percentage changes for both in the south (England and Wales), with smaller changes toward the north. This is in line with the conclusions of Lowe et al. 2018 which project the UK will experience drier summers and wetter winters in the future.

Projections of drought, based solely on rainfall deficit, show a reduction in the North and West UK and increase in the South and East UK. Increases could impact on water available for crop growth, an important consideration for the agricultural industry. In England and Wales, 
where projected changes are larger, the adaptation of water management practices is expected to be required to cope with the increased severity of drought.

The analysis of our rainfall impact metrics based on the National Severe Weather Warning Service criteria has found that projections show increases in the high-impact heavy rainfall suggesting more frequent river flooding having widespread severe impacts across the UK. For the metrics with moderate- and lower-impact thresholds, the relative trend is progressively smaller. The main reason for this is because the metric with the higher impact threshold, by definition, describes rarer events - so smaller increases result in a larger fractional change in the number of events per year. Increases in the number of both moderate and high events at increased global temperature levels are similar.

We also looked at wind impact metrics, based on the National Severe Weather Warning Service criteria for maximum wind gust speed at a height of $10 \mathrm{~m}$. Specifically, measuring the frequency of exceeding regionally varying thresholds for low/medium/high impacts (such as transport disruption, infrastructure or building damage, bridge collapse and trees falling). These results are not shown as they displayed very little trend compared to natural variability, meaning it is not possible to detect a "climate signal" as interannual differences in the wind gusts are larger than any trend in the data. Our wind analysis was also limited by not having a corresponding observational dataset against which to bias adjust the model output, so unadjusted model data was used. This - combined with the parameterization of gust speeds, the difficulty of modelling wind gusts and the localized effects of orography, even at 12-km resolution - meant that we have much lower confidence in this result than those for other metrics examined in this report. Moemken et al. (2018) look at wind speeds relevant to the wind energy sector, and they also only find small changes in future wind speeds with large model biases. However, Moemken et al. (2018) did identify an increase in wind speed variability in the future which could have implications for wind energy management.

We find similar results to impacts studies using the EURO-CORDEX regional climate simulations (Jacob et al. 2014) which are run at a similar resolution (12.5 km). The Dosio (2016) future projections of end of century extreme temperature and precipitation indices with EURO-CORDEX, including frost days, tropical nights, summer days and icing days, are consistent with ours and confirmed the necessity for threshold-based indices to be bias adjusted. The Spinoni et al. (2018) analysis of droughts with EURO-CORDEX found the whole of Europe will be affected by more frequent and severe droughts under RCP8.5.

Another recent study (Arnell et al. 2020) has also looked at indicators of climate change impacts using UKCP but focused on the probabilistic forecasts and global model simulations. They also looked at results on pathways to $2{ }^{\circ} \mathrm{C}, 3{ }^{\circ} \mathrm{C}$ and $4{ }^{\circ} \mathrm{C}$ at the end of the twenty-first century, a different definition of warming levels to that used here. Results from Arnell et al. (2020) are based on the probabilistic UKCP product rather than the RCM used here, but the median projections for the three common metrics (heating degree days, cooling degree days, growing degree days) agree well for each region of the UK (See the Arnell et al. 2020 supplementary material and Fig. 10 from Arnell et al. 2020).

When using the results presented here, it is important to consider that our understanding and ability to simulate the climate is advancing all the time. Our climate models are not able to represent all the features seen in the present-day real climate, and there are still limitations in our ability to project twenty-first-century weather and climate. We recommend that future research examines the impacts from the latest UKCP Local simulations at $2.2 \mathrm{~km}$, which is approaching the resolution of weather forecast models. In particular, once the latest version of these simulations is finalized in 2021, it would be useful to repeat some of the analysis with the 
2.2-km simulations, to study whether increased local resolution changes the results. Further analysis of the rainfall metrics with the $2.2-\mathrm{km}$ simulations would be most beneficial as initial results show this convection-permitting model has led to great improvement in the modelling of UK rainfall (Kendon et al. 2019). However, an intercomparison between our results using the $12-\mathrm{km}$ regional model and the $2.2-\mathrm{km}$ data will not be able to use fixed warming levels because the $2.2 \mathrm{~km}$ are only provided initially at fixed time-slice periods and so do not easily lend themselves to examining global warming levels. It will also be advantageous to perform a future intercomparison with the highest-resolution global model simulations from HighResMIP (Haarsma et al. 2016). Together, this further research will help to understand whether improvements to modelling local impacts will be more driven by improvements to global models driving the regional synoptic situation or from the local downscaling improvements.

By using the same thresholds in our impact relevant thresholds for future periods, we are implicitly assuming that vulnerability does not change in future and we do not consider the effects of adaptation measures that might reduce the future impacts of severe weather. This limits our ability to fully assess all the positive and negative impacts that the UK might experience due to global warming. As our understanding of the climate system and our ability to model it improves, both the model projections and probability distribution for a given outcome are likely to evolve in the future. So, important risk assessments and any adaptation strategies to build resilience are flexible in order to be effective as our understanding of these risks evolves.

In summary, we have considered future extremes and impacts at a range of global mean warming levels which span the aims of the Paris Agreement and warming levels implied by plausible scenarios consistent with the current nationally determined contributions (NDCs). If mitigation actions in the NDC are intensified globally, the upper warming level projections in this study could be avoided. However, the results also show that we cannot rely on global mitigation effects alone. The increasing impacts associated with extreme events as the globe warms highlight the need for long-term planning and risk assessment activities across sectors.

Supplementary Information The online version contains supplementary material available at https://doi.org/ 10.1007/s10584-021-03100-5.

Code availability N/A.

Author contribution Helen Hanlon, Dan Bernie and Jason Lowe contributed to the study conception and design. Manuscript preparation, data collection and analysis were performed by Helen Hanlon, Dan Bernie and Giulia Carigi. The first draft of the manuscript was written by Helen Hanlon, and all authors commented on the previous versions of the manuscript. All authors read and approved the final manuscript.

Funding This work was supported by the Met Office Hadley Centre Climate Programme funded by BEIS and Defra, as well as the UK Climate Resilience Programme led jointly by the Met Office and UK Research and Innovation (UKRI) Strategic Priorities Fund UK Climate Resilience Programme. The UKRI programme is codelivered by Met Office and NERC on behalf of the UKRI partners AHRC, EPSRC and ESRC.

Data availability UKCP18 12-km simulations used in this study are available online; see more details here: https://www.metoffice.gov.uk/research/approach/collaboration/ukcp/download-data.

\section{Declarations}


Consent to participate This research has not involved any human or animal participants; it was entirely performed with computational modelling. All authors have reviewed the manuscript and consent to publication.

Conflict of interest The authors declare no competing interests.

Open Access This article is licensed under a Creative Commons Attribution 4.0 International License, which permits use, sharing, adaptation, distribution and reproduction in any medium or format, as long as you give appropriate credit to the original author(s) and the source, provide a link to the Creative Commons licence, and indicate if changes were made. The images or other third party material in this article are included in the article's Creative Commons licence, unless indicated otherwise in a credit line to the material. If material is not included in the article's Creative Commons licence and your intended use is not permitted by statutory regulation or exceeds the permitted use, you will need to obtain permission directly from the copyright holder. To view a copy of this licence, visit http://creativecommons.org/licenses/by/4.0/.

\section{References}

Arbuthnott KG, Hajat S (2017) The health effects of hotter summers and heat waves in the population of the United Kingdom: a review of the evidence. Environ Health 16(Suppl 1):1-13. https://doi.org/10.1186/ s12940-017-0322-5

Arnell NW, Lowe JA, Lloyd-Hughes B, Osborn TJ (2018) The impacts avoided with a $1.5^{\circ} \mathrm{C}$ climate target: a global and regional assessment. Clim Chang 147(1-2):61-76. https://doi.org/10.1007/s10584-017-2115-9

Arnell NW, Kay AL, Freeman A, Rudd AC, Lowe JA (2020) Changing climate risk in the UK: a multi-sectoral analysis using policy-relevant indicators. Clim Risk Manag. https://doi.org/10.1016/j.crm.2020.100265

Barlow KM, Christy BP, O’Leary GJ, Riffkin PA, Nuttall JG (2015) Simulating the impact of extreme heat and frost events on wheat crop production: a review. Field Crop Res 171:109-119. https://doi.org/10.1016/j.fcr. 2014.11.010

Basu R (2009) High ambient temperature and mortality: a review of epidemiologic studies from 2001 to 2008. Environ Health 8:40. https://doi.org/10.1186/1476-069X-8-40

Blenkinsop S, Fowler HJ (2007) Changes in European drought characteristics projected by the PRUDENCE regional climate models. Int J Climatol 27:1595-1610. https://doi.org/10.1002/joc. 1538

Bryant SJ, Arnell NW, Law FM (1992) The long-term context for the current hydrological drought. In: Proceedings of the IWEM Conference on the Management of Scarce Water Resources

Cannon AJ, Sobie SR, Murdock TQ (2015) Bias correction of GCM precipitation by quantile mapping: how well do methods preserve changes in quantiles and extremes? J Clim 28:6938-6959. https://doi.org/10.1175/ JCLI-D-14-00754.1

CCC (2016) Annex 2. Heat in UK buildings today Committee on Climate Change 1-26 https://www. theccorguk/wp-content/uploads/2017/01/Annex-2-Heat-in-UK-Buildings-Today-Committee-on-ClimateChange-October-2016pdf. Accessed 15 January 2021

CCC (2017) CCRA UK 2017 report. Synthesis report: priorities for the next five years Committee on Climate Change https://www.theccorguk/wp-content/uploads/2016/07/UK-CCRA-2017-Synthesis-ReportCommittee-on-Climate-Changepdf. Accessed 15 January 2021

Cole GA, Marsh TJ (2006). The impact of climate change on severe droughts. In Using science to create a better place, Environment Agency Science Report SC040068/SR1 https://www.assetspublishingservicegovuk/ government/uploads/system/uploads/attachment_data/file/290832/scho1206blsm-e-epdf. Accessed 15 January 2021

Cook C with contributions from, Gavin H, Berry P, Guillod B, Lange B, Rey Vicario D, Whitehead P (2017) Drought planning in England: a primer. Environmental Change Institute, University of Oxford, UK

Dosio A (2016) Projections of climate change indices of temperature and precipitation from an ensemble of biasadjusted high-resolution EURO-CORDEX regional climate models. J Geophys Res 121:5488-5511. https:// doi.org/10.1002/2015JD024411

Field S (1992) The effect of temperature on crime. Br J Criminol 32(3):340-351. https://doi.org/10.1093/ oxfordjournals.bjc.a048222

Fowler HJ, Wilby RL (2010) Detecting changes in seasonal precipitation extremes using regional climate model projections: implications for managing fluvial flood risk. Water Resour Res 46(3):1-17. https://doi.org/10. 1029/2008WR007636 
Gohar LK, Lowe JA, Bernie D (2017) The impact of bias correction and model selection on passing temperature Thresholds. J Geophys Res-Atmos 122(22):12045-12061

Gohar LK, Bernie D, Good P, Lowe JA (2018) UKCP18 derived projections of future climate over the UK, Met Office. https://www.metoffice.gov.uk/pub/data/weather/uk/ukcp18/science-reports/UKCP18-DerivedProjections-of-Future-Climate-over-the-UK.pdf. Accessed 15 January 2021

Gosling SN, McGregor GR, Páldy A (2007) Climate change and heat-related mortality in six cities part 1: model construction and validation. Int J Biometeorol 51(6):525-540. https://doi.org/10.1007/s00484-007-0092-9

Haarsma RJ, Roberts MJ, Vidale PL et al (2016) High resolution model intercomparison project (HighResMIP v1.0) for CMIP6. Geosci Model Dev 9:4185-4208. https://doi.org/10.5194/gmd-9-4185-2016

Harvey LDD (2020) Using modified multiple heating-degree-day (HDD) and cooling-degree-day (CDD) indices to estimate building heating and cooling loads. Energy Build 229:110475

HM Government (2020) National Risk Register 2020 edition, HM Government. https://assets.publishing.service. gov.uk/government/uploads/system/uploads/attachment_data/file/952959/6.6920_CO_CCS_s_National_ Risk_Register_2020_11-1-21-FINAL.pdf. Accessed 15 January 2021

Horrocks J, Menclova AK (2011) The effects of weather on crime. N Z Econ Pap 45(3):231-254. https://doi.org/ $10.1080 / 00779954.2011 .572544$

IPCC (2018) SR15, Global Warming of $1.5^{\circ} \mathrm{C}$. An IPCC Special Report on the impacts of global warming of $1.5^{\circ} \mathrm{C}$ above pre-industrial levels and related global greenhouse gas emission pathways, in the context of strengthening the global response to the threat of climate change, sustainable development, and efforts to eradicate poverty [V. Masson-Delmotte, P. Zhai, H. O. Pörtner, D. Roberts, J. Skea, P.R. Shukla, A. Pirani, W. Moufouma-Okia, C. Péan, R. Pidcock, S. Connors, J. B. R. Matthews, Y. Chen, X. Zhou, M. I. Gomis, E. Lonnoy, T. Maycock, M. Tignor, T. Waterfield (eds.)]. In Press. IPCC. https://www.ipcc.ch/sr15/. Accessed 15 January 2021

Jacob D, Petersen J, Eggert B, Alias A, Christensen OB, Bouwer LM, ... Yiou P (2014). EURO-CORDEX: New high-resolution climate change projections for European impact research. Reg Environ Chang, 14(2): 563578. https://doi.org/10.1007/s10113-013-0499-2

James R, Washington R, Schleussner CF, Rogelj J, Conway D (2017) Characterizing half-a-degree difference: a review of methods for identifying regional climate responses to global warming targets. Wiley Interdiscip Rev Clim Chang 8(2):e457. https://doi.org/10.1002/wcc.457

Jaroszweski D, Hooper E, Chapman L (2014) The impact of climate change on urban transport resilience in a changing world. Prog Phys Geogr 38(4):448-463. https://doi.org/10.1177/0309133314538741

Jaroszweski D, Hooper E, Baker C, Chapman L, Quinn A (2015) The impacts of the 28 June 2012 storms on UK road and rail transport. Meteorol Appl 22(3):470-476. https://doi.org/10.1002/met.1477

Kendon E, Roberts NM, Fowler HJ, Chan S, Senior C (2014) Nat Clim Chang 4:570-576. https://doi.org/10. 1038/nclimate2258

Kendon E, Fosser G, Murphy J, Chan S, Clark R, Harris G, Lock A, Lowe A, Martin G, Pirret J, Roberts N, Sanderson M, Tucker S (2019) UKCP convection-permitting model projections: science report, Met Office, https:/www.metofficegovuk/pub/data/weather/uk/ukcp18/science-reports/UKCP-Convection-permittingmodel-projections-reportpdf. Accessed 15 January 2021

Kendon M, McCarthy M, Jevrejeva S, Matthews A, Sparks T, Garforth J (2020) State of the UK climate 2019. Int J Climatol 40(S1):1-69. https://doi.org/10.1002/joc.6726

Kjellström E, Nikulin G, Strandberg G et al (2018) European climate change at global mean temperature increases of 1.5 and $2{ }^{\circ} \mathrm{C}$ above pre-industrial conditions as simulated by the EURO-CORDEX regional climate models. Earth Sys Dyn 9(2):459-478. https://doi.org/10.5194/esd-9-459-2018

Lowe JA, Bernie D, Bett PE, et al (2018) UKCP18 science overview report. Met Office https://www. metofficegovuk/pub/data/weather/uk/ukcp18/science-reports/UKCP18-Overview-reportpdf. Accessed 15 January 2021

Mares D (2013) Climate change and crime: Monthly temperature and precipitation anomalies and crime rates in St. Louis, MO 1990-2009. Crime Law Soc Chang 59(2):185-208. https://doi.org/10.1007/s10611-0139411-8

McCarthy, M, Christidis, N, Dunstone, N, et al. (2019). Drivers of the UK summer heatwave of 2018. Weather wea.3628. https://doi.org/10.1002/wea.3628

Met Office (2018) State of the UK climate 2017: supplementary report on climate extremes. https://www. metofficegovuk/binaries/content/assets/metofficegovuk/pdf/weather/learn-about/uk-past-events/state-of-ukclimate/soc supplement-002pdf. Accessed 15 January 2021

Mishra AK, Singh VP (2010) A review of drought concepts. J Hydrol 391:202-216. https://doi.org/10.1016/j. jhydrol.2010.07.012

Moemken J, Reyers M, Feldmann H, Pinto JG (2018) Future changes of wind speed and wind energy potentials in EURO-CORDEX ensemble simulations. J Geophys Res:Atmos 123(12):6373-6389. https://doi.org/10. 1029/2018JD028473 
Murage P, Hajat S, Kovats RS (2017) Effect of night-time temperatures on cause and age-specific mortality in London. Environ Epidemiol 1(2):e005. https://doi.org/10.1097/EE9.0000000000000005

Murphy JM, Harris GR, Sexton DMH, et al (2018) UKCP18 land projections: science report. Met Office https:// www.metofficegovuk/pub/data/weather/uk/ukcp18/science-reports/UKCP18-Land-reportpdf. Accessed 15 January 2021

ONS (2018) Quarterly mortality report, England: July to September 2018, Office for National Statistics https:// www.onsgovuk/peoplepopulationandcommunity/birthsdeathsandmarriages/deaths/articles/ quarterlymortalityreports/julytoseptember2018. Accessed 15 January 2021

Palin EJ, Thornton HE, Mathison CT, McCarthy RE, Clark RT, Dora J (2013) Future projections of temperaturerelated climate change impacts on the railway network of Great Britain. Clim Chang 120(1-2):71-93. https://doi.org/10.1007/s10584-013-0810-8

Phillips I, McGregor A (1998) The utility of a drought index for assessing the drought hazard in Devon and Cornwall, South West England. Meteorol Appl 5(4):359-372. https://doi.org/10.1017/S1350482798000899

Rahiz M, New M (2013) 21st century drought scenarios for the UK. Water Resour Manag 27(4):1039-1061. https://doi.org/10.1007/s11269-012-0183-1

Ranson M (2014) Crime, weather, and climate change. J Environ Econ Manag 67(3):274-302. https://doi.org/10. 1016/j.jeem.2013.11.008

Schleussner CF, Lissner TK, Fischer EM et al (2016) Differential climate impacts for policy-relevant limits to global warming: the case of $1.5^{\circ} \mathrm{c}$ and $2{ }^{\circ} \mathrm{c}$. Earth Syst Dyn 7(2):327-351. https://doi.org/10.5194/esd-7$327-2016$

Spinoni J, Vogt JV, Naumann G, Barbosa P, Dosio A (2018) Will drought events become more frequent and severe in Europe? Int J Climatol 38(4):1718-1736. https://doi.org/10.1002/joc.5291

Stevens HR, Beggs PJ, Graham PL, Chang HC (2019) Hot and bothered? Associations between temperature and crime in Australia. Int J Biometeorol 63(6):747-762. https://doi.org/10.1007/s00484-019-01689-y

Switanek MB, Troch PA, Castro CL, Leuprecht A, Chang HI, Mukherjee R, Demaria EMC (2017) Scaled distribution mapping: a bias correction method that preserves raw climate model projected changes. Hydrol Earth Syst Sci 21:2649-2666. https://doi.org/10.5194/hess-21-2649-2017

Water UK (2018) Briefing paper on managing water supplies during summer 2018 and preparing for 2019. https://www.water.org.uk/wp-content/uploads/2018/12/Briefing-Paper-Summer-and-Winter-191218.pdf. Accessed 15 January 2021

Wood FR, Calverley D, Glynn S, Mander S, Walsh C, Kuriakose J, Hill F, Roeder M (2015) The impacts of climate change on UK energy demand. Infrastruct Asset Manag 2(3):107-119. https://doi.org/10.1680/ iasma.14.00039

Xu R, Xiong X, Abramson MJ, Li S, Guo Y (2020) Ambient temperature and intentional homicide: a multi-city case-crossover study in the US. Environ Int 143(March):105992. https://doi.org/10.1016/j.envint.2020. 105992

Publisher's note Springer Nature remains neutral with regard to jurisdictional claims in published maps and institutional affiliations.

\section{Affiliations}

\section{Helen M. Hanlon ${ }^{1}$ - Dan Bernie ${ }^{1}$ - Giulia Carigi ${ }^{1,2}$ - Jason A. Lowe ${ }^{1,3}$}

1 Met Office, Exeter, UK

2 University of Reading, Reading, UK

3 Priestley International Centre for Climate, University of Leeds, Leeds, UK 